\title{
Lack of association between glutathione s-transferase mu 1 (GSTM1) gene polymorphisms and obesity
}

\author{
Seung-Ae Yang* \\ College of Nursing, Sungshin Women's University, Seoul, Korea
}

Recent researches suggested that personal individual's genetic background is contributed to the susceptibility to obesity. The present of this study is to investigate whether single nucleotide polymorphisms (SNPs) of glutathione s-transferase mu 1 (GSTM1) gene are susceptibility to obesity in Korean population. In present study, two SNPs (rs1056806 [Asp142Asp], rs3815029 [promoter]) of GSTM1 gene were genotyped in 117 overweight/obese subjects with a body mass index $(B M I) \geq 23 \mathrm{~kg} / \mathrm{m}^{2}$ and 125 nonoverweight/obese with a BMl of $18.5-23.0 \mathrm{~kg} / \mathrm{m}^{2}$. Genotyping of two SNPs (rs1056806 and rs3815029) was determined by sequencing after polymerase chain reaction. Logistic regression models (codominant, dominant, recessive, and log-additive models) and allele

\section{INTRODUCTION}

Obesity is a state in which excess fat is accumulated in the body to cause abnormalities in health (Goodarzi, 2017). Obesity itself is a cause of many chronic diseases including stroke and is one of the health-threatening factors (Kalantari et al., 2016; Zhou et al., 2017). In recent years, the overall obesity population is rapidly increasing due to a decrease in physical activity and an increase in energy consumption. The increase in the obese population is associated with an increased incidence of diverse diseases such as diabetes (Mutie et al., 2017), cardiovascular disease (Shaw et al., 2017), cancer (colon cancer, breast cancer, prostate cancer, etc.) (Engin, 2017; Fardet et al., 2017), dyslipidemia, and osteoarthritis. Obesity is a burden on individual health care costs and national health care costs (Tremmel et al., 2017). This aspect is a common phenomenon not only in European countries such as England and France, but also in countries around the world including Asia (Hoque et al., 2016; Kim and Basu, 2016). analysis were used to calculate odds ratio, $95 \%$ confidence interval, and $P$-values. Significant association was considered at $P<0.05$. Tested two SNPs in GSTM1 genes did not show any significant association with obesity (rs1056806, $P=0.24$ in codominant 1 model; rs3815029, $P=0.59$ in codominant $1, P=0.09$ in codominant $2, P=0.16$ in dominant, $P=0.09$ in recessive, and $P=0.07$ in log-additive models). In summary, these results indicate that SNPs of GSTM1 gene did not associated with susceptibility of obesity in the Korean population.

Keywords: Overweight, Obese, Obesity, GSTM1, Single nucleotide polymorphism
The cause of obesity has recently been proposed to be related to complex, multifactorial biological and environmental factors (Bell, 2017; O'Rahilly and Farooqi, 2000). From a biological point of view, obesity is known to determine physiological and genetic, race, sex, and age. Regarding to association between obesity and genetic backgroud, when one of the identical twins is obese, the other is much more likely to be obese than the fraternal twin 28845613. In addition, the statistic that obesity correlations between parents and patients are stronger than the relationship between parents and progenitors is evidence that obesity is affected by genetic factors (O'Rahilly and Farooqi, 2000).

Glutathione (GST) genes are phase II enzymes involved in the detoxification of intrinsic and extrinsic electrophilic compounds, which protect against oxidative stress by eliminating free radicals by glutathione-dependent peroxidase and affect individual susceptibility to diseases such as hypertension (Ge et al., 2015). Genetic polymorphisms of the glutathione s-transferase mu 1 (GSTM1) gene are known to affect DNA and antioxidant levels (Altay and
${ }^{*}$ Corresponding author: Seung-Ae Yang (iD https://orcid.org/0000-0002-6235-2752 College of Nursing, Sungshin Women's University, 55 Dobong-ro 76ga-gil, Gangbuk-gu, Seoul 01133, Korea

Tel: +82-2-920-7728, Fax: +82-2-920-2092, E-mail: ewha63@sungshin.ac.kr Received: September 30, 2017 / Accepted: October 12, 2017
This is an Open Access article distributed under the terms of the Creative Commons Attribution Non-Commercial License (http://creativecommons.org/licenses/by-nc/4.0/) which permits unrestricted non-commercial use, distribution, and reproduction in any medium, provided the original work is properly cited. 
Bozoğlu, 2017).

Genetic polymorphisms of specific genes are known to be associated with obesity in recent years and many studies are under way (Akbarian et al., 2017; Liu et al., 2017; Rivera et al., 2017). In present study, we investigated the relationship between GSTM1 gene polymorphisms and obesity.

\section{MATERIALS AND METHODS}

\section{Study subjects}

Table 1 shows clinical and biochemical characteristics of overweight/obese and control subjects. In the present study, 117 overweight/obese subjects and 125 nonoverweight/obese subjects were recruited. These subjects were recruited among participants that examined a general health check-up program. Subjects with severe diseases such as stroke, psychiatric disorders, and cancers were excluded. The biochemical characteristics of individuals were measured such as fasting plasma glucose, fasted glycated hemoglobin, high-density lipoprotein. Body mass index (BMI) is calculated as weight $(\mathrm{kg})$ divided by the square of height $(\mathrm{m})$. According to the classification of Korean Society for the Study of Obesity (underweight, BMI $<18 \mathrm{~kg} / \mathrm{m}^{2}$; normal, BMI 18 to $<23 \mathrm{~kg} / \mathrm{m}^{2}$; moderately obese, BMI 23 to $<25 \mathrm{~kg} / \mathrm{m}^{2}$; obesity I, BMI 25 to $<30 \mathrm{~kg} / \mathrm{m}^{2}$; obesity II, BMI $\geq 30 \mathrm{~kg} / \mathrm{m}^{2}$ ), subjects were divided into 2 subgroups, the overweight/obese group (BMI $\geq 23 \mathrm{~kg} / \mathrm{m}^{2}$ ) and the control group $\left(18 \mathrm{~kg} / \mathrm{m}^{2} \leq \mathrm{BMI}<23 \mathrm{~kg} / \mathrm{m}^{2}\right)$.

\section{SNP selection and genotyping}

Peripheral bloods of all subjects were collected in ethylenediaminetetraacetic acid or heparin tube. Genomic DNAs were extracted by QIAamp DNA mini kit (QIAGEN, Valencia, CA, USA). We selected two SNPs (rs1056806 [Asp142Asp], rs3815029 [promoter]) in GSTM1 gene. Genotype of each SNP was performed by sequencing after polymerase chain reaction (PCR).

Table 1. Clinical and biochemical characteristics of overweight/obese and control subjects.

\begin{tabular}{lcc}
\hline Characteristic & $\begin{array}{c}\text { Overweight/obese } \\
(\mathrm{n}=117)\end{array}$ & $\begin{array}{c}\text { Control } \\
(\mathrm{n}=125)\end{array}$ \\
\hline Age $(\mathrm{yr})$ & $44.2 \pm 14.1$ & $35.2 \pm 11.3$ \\
Body mass index $\left(\mathrm{kg} / \mathrm{m}^{2}\right)$ & $25.5 \pm 2.3$ & $20.6 \pm 1.3$ \\
Fasting plasma glucose $(\mathrm{mg} / \mathrm{dL})$ & $91.6 \pm 22.7$ & $85.1 \pm 8.6$ \\
High-density lipoprotein $(\mathrm{mg} / \mathrm{dL})$ & $49.6 \pm 10.7$ & $54.9 \pm 11.7$ \\
Glycated hemoglobin $(\%)$ & $5.8 \pm 0.7$ & $5.4 \pm 0.5$ \\
Triglyceride $(\mathrm{mg} / \mathrm{dL})$ & $191.7 \pm 32.9$ & $170.8 \pm 26.2$ \\
\hline
\end{tabular}

Values are presented as mean \pm standard deviation.
The primers used for PCR are as follows; rs1056806, sense, 5'AAGGAGGAGTGATATGGGGAAT-3', antisense, 5'-GTGGCATGAAACCAGTACTCAA-3’; rs3815029, sense, 5’-TGACACTGTTCCTGTGTAGG-3' and antisense, 5'-GATCTGGCTGGTGTCTCAAG-3).

\section{Statistical analysis}

SNPStats (http://bioinfo.iconcologia.net/index.php) and IBM SPSS Statistics ver. 23.0 (IBM Co., Armonk, NY, USA) were used to determine the odds ratio (OR), 95\% confidence interval (CI), and $P$-value. Logistic regression models (codominant $1[\mathrm{~A} / \mathrm{A}$ genotype vs. A/B genotype], codominant 2 [A/A genotype vs. B/B genotype], dominant $[\mathrm{A} / \mathrm{A}$ genotype vs. $\mathrm{A} / \mathrm{B}$ genotype $+\mathrm{B} / \mathrm{B}$ genotype], recessive [A/A genotype $+\mathrm{A} / \mathrm{B}$ genotype vs. $\mathrm{B} / \mathrm{B}$ genotype], and $\log$-additive models [A/A genotype vs. $\mathrm{A} / \mathrm{B}$ genotype vs. $\mathrm{B} / \mathrm{B}$ genotype]) were applied. The $P$-value below 0.05 was considered significant.

\section{RESULTS}

In order to evaluate the association between GSTM1 gene and susceptibility of obesity, we genotyped and analyzed the one exonic SNP (rs1056806) and one promoter SNP (rs3815029) of GSTM1 gene.

Table 2 showed genotypic distributions of two SNPs of GSTM1 gene in the control group and overweight/obese group. The $\mathrm{C} / \mathrm{C}$ genotype:T/C genotype:T/T genotype of rs1056806 in the overweight/obese group and the control group were 90.8\%:9.2\%: 0.0\% and 93.6\%:6.4\%:0.0\%. And the $\mathrm{C} / \mathrm{C}$ genotype:C/G genotype:G/G genotype of rs3815029 in the overweight/obese group and the control group were 42.4\%:45.6\%:12.0\% and 48.7\%: 45.34\%:6.0\%. In genotypic analysis, two SNPs did not be observed any significant association with susceptibility of obesity (rs1056806: OR, 0.62; 95\% CI, 0.28-1.36; $P=0.24$ in codominant 1 model [C/C genotype vs. $\mathrm{C} / \mathrm{T}$ genotype] and rs3815029: OR, 0.75 ; 95\% CI, 0.41-1.36; $P=0.59$ in codominant 1 model [C/C genotype vs. C/G genotype]; OR, 0.36; 95\% CI, 0.12-1.07; $P=0.09$ in codominant 2 model $[\mathrm{C} / \mathrm{C}$ genotype vs. G/G genotype]; OR, 0.66; 95\% CI, 0.37-1.18; $P=0.16$ in dominant model $[\mathrm{C} / \mathrm{C}$ genotype vs. $\mathrm{C} / \mathrm{G}$ genotype $+\mathrm{G} / \mathrm{G}$ genotype]; OR, 0.42 ; 95\% CI, 0.15-1.19; $P=0.09$ in recessive model [C/C genotype + $\mathrm{C} / \mathrm{G}$ genotype vs. $\mathrm{G} / \mathrm{G}$ genotype]; and $\mathrm{OR}, 0.66$; $95 \%$ CI, $0.42-$ $1.03 ; P=0.07$ in $\log$-additive model $[\mathrm{C} / \mathrm{C}$ genotype vs. $\mathrm{C} / \mathrm{G}$ genotype vs. $G / G$ genotype]).

In allele analysis, allele frequencies of the each SNP in GSTM1 
Table 2. Genotypic distributions of single nucleotide polymorphisms of glutathione s-transferase mu 1 (GSTM1) gene in the control group and overweight/obese group

\begin{tabular}{|c|c|c|c|c|c|c|}
\hline SNP & Genotype & Control & Overweight/obese & Models & OR (95\% CI) & $P$-value \\
\hline \multirow[t]{5}{*}{ rs1056806 } & $C / C$ & $102(81.6)$ & 102 (87.2) & Codominant 1 & $0.62(0.28-1.36)$ & 0.24 \\
\hline & $\mathrm{C} / \mathrm{T}$ & $23(18.4)$ & $15(12.8)$ & Codominant 2 & NA & NA \\
\hline & $\mathrm{T} / \mathrm{T}$ & $0(0.0)$ & $0(0.0)$ & Dominant & NA & NA \\
\hline & & & & Recessive & NA & NA \\
\hline & & & & Log-additive & NA & NA \\
\hline \multirow[t]{5}{*}{ rs3815029 } & $\mathrm{C} / \mathrm{C}$ & $53(42.4)$ & $57(48.7)$ & Codominant 1 & $0.75(0.41-1.36)$ & 0.59 \\
\hline & $C / G$ & $57(45.6)$ & $53(45.3)$ & Codominant 2 & $0.36(0.12-1.07)$ & 0.09 \\
\hline & $\mathrm{G} / \mathrm{G}$ & $15(12.0)$ & $7(6.0)$ & Dominant & $0.66(0.37-1.18)$ & 0.16 \\
\hline & & & & Recessive & $0.42(0.15-1.19)$ & 0.09 \\
\hline & & & & Log-additive & $0.66(0.42-1.03)$ & 0.07 \\
\hline
\end{tabular}

Genotype distributions are presented as number (\%).

$P$-values were from logistic regression analyses with the codominant, dominant, recessive, and log-additive models.

SNP, single nucleotide polymorphism; OR, odds ratio; $\mathrm{Cl}$, confidence interval; NA, not applicable.

Table 3. Allele distributions of single nucleotide polymorphisms of glutathione s-transferase mu 1 (GSTM1) gene in the control group and overweight/obese group

\begin{tabular}{lccccc}
\hline SNP & Allele & Control & Overweight/obese & OR (95\% Cl) & P-value \\
rs1056806 & C & $227(90.8)$ & $219(93.6)$ & 1 & $0.68(0.34-1.33)$ \\
rs3815029 & T & $23(9.2)$ & $15(6.4)$ & $167(71.4)$ & 0.26 \\
& C & $163(65.2)$ & $67(28.6)$ & $0.75(0.51-1.10)$ & 0.15 \\
\hline
\end{tabular}

Genotype distributions are presented as number (\%).

$P$-values were from logistic regression analyses.

SNP, single nucleotide polymorphism; OR, odds ratio; Cl, confidence interval; NA, not applicable.

gene were compared between the control group and the overweight/obese group by logistic regression analysis in Table 3 . The C allele:T allele of rs1056806 in the overweight/obese group and the control group were 90.8\%:9.2\% and 93.6\%:6.4\% and $\mathrm{C}$ allele:G allele of rs3815029 in the overweight/obese group and the control group were 65.2\%:34.8\% and 71.4\%:28.6\%. The differences of each SNP distributions in two groups also did not show any significant association with obesity.

\section{DISCUSSION}

The most famous gene related to genetic polymorphism and obesity is known as FTO gene and there are many studies (Moghanloo et al., 2017; Rivera et al., 2017; Zhou et al., 2017). Although genetic polymorphism alone affects certain diseases, a combination of polymorphisms of several genes is known to affect disease. Therefore, it is necessary to identify candidate genes for obesity.

GSMT1 is known to be associated with oxidative stress. Excessive oxidative stress results in cellular damage and physiological anomalies. This oxidative stress is considered to have a direct impact on the pathogenesis and progression of major diseases such as obesity, cancer, arteriosclerosis, coronary artery disease, and rheumatoid arthritis, which frequently occur in modern society (Niemann et al., 2017; Reho and Rahmouni, 2017).

There were several studies about GSTM1 gene polymorphisms and diseases. The rs1056806 SNP was previously included in the study of GSTM1 deletion and bladder cancer association using SNP-array, however the researchers did not found any significant association of rs1056806 with bladder cancer (Marenne et al., 2012). The second SNP in this research rs3815029, was studied in the study of allergy or asthma of urban dwelling African American (Joubert et al., 2011), however rs3815029 SNP itself was not significant with general development of allergy, asthma or related diagnostic values. Additionally, rs3815029 was studied in a bladder cancer study, by another group of researchers. The rs3815029 SNP itself was not significant, and the researchers showed that rs3815029 may be influenced by a haplotype which is consisted along with rs412543 and $-471 \mathrm{C}>\mathrm{T}$ which are also in chromosome 1 (1p13.3) (Zhang et al., 2012). Besides, each study results were not showing replicated results of SNPs (Zhang et al., 2012) The present study was also observed that tested two polymorphisms (rs1056806 and rs3815029) of GSTM1 gene were not 
significantly associated with development of obesity.

Our study has limitations. Only a small Korean population of obesity was analyzed, and other polymorphisms were not integrated in this study. In summary, the results of present study suggest that polymorphisms of GSTM1 gene did not associated with susceptibility of obesity in Korean population.

\section{CONFLICT OF INTEREST}

No potential conflict of interest relevant to this article was reported.

\section{REFERENCES}

Akbarian SA, Salehi-Abargouei A, Pourmasoumi M, Kelishadi R, Nikpour $\mathrm{P}$, Heidari-Beni M. Association of brain-derived neurotrophic factor gene polymorphisms with body mass index: A systematic review and meta-analysis. Adv Med Sci 2017;63:43-56.

Altay A, Bozoğlu F. Salvia fruticosa modulates mRNA expressions and activity levels of xenobiotic metabolizing CYP1A2, CYP2E1, NQO1, GPx, and GST enzymes in human colorectal adenocarcinoma HT-29 cells. Nutr Cancer 2017;69:892-903.

Bell CG. The epigenomic analysis of human obesity. Obesity (Silver Spring) 2017;25:1471-1481.

Engin A. Obesity-associated breast cancer: analysis of risk factors. Adv Exp Med Biol 2017;960:571-606.

Fardet A, Druesne-Pecollo N, Touvier M, Latino-Martel P. Do alcoholic beverages, obesity and other nutritional factors modify the risk of familial colorectal cancer? A systematic review. Crit Rev Oncol Hematol 2017 Sep 7 [Epub]. https://doi.org/10.1016/j.critrevonc.2017.09.001.

Ge B, Song Y, Zhang Y, Liu X, Wen Y, Guo X. Glutathione S-transferase M1 (GSTM1) and T1 (GSTT1) null polymorphisms and the risk of hypertension: a meta-analysis. PLoS One 2015;10:e0118897.

Goodarzi MO. Genetics of obesity: what genetic association studies have taught us about the biology of obesity and its complications. Lancet Diabetes Endocrinol 2017 Sep 14 [Epub]. https://doi.org/10.1016/ S2213-8587(17)30200-0.

Hoque ME, Mannan M, Long KZ, Al Mamun A. Economic burden of underweight and overweight among adults in the Asia-Pacific region: a systematic review. Trop Med Int Health 2016;21:458-469.

Joubert BR, Reif DM, Edwards SW, Leiner KA, Hudgens EE, Egeghy P, Gallagher JE, Hubal EC. Evaluation of genetic susceptibility to childhood allergy and asthma in an African American urban population. BMC Med Genet 2011;12:25.

Kalantari N, Doaei S, Keshavarz-Mohammadi N, Gholamalizadeh M,
Pazan N. Review of studies on the fat mass and obesity-associated (FTO) gene interactions with environmental factors affecting on obesity and its impact on lifestyle interventions. ARYA Atheroscler 2016; 12:281-290.

Kim DD, Basu A. Estimating the medical care costs of obesity in the United States: systematic review, meta-analysis, and empirical analysis. Value Health 2016;19:602-613.

Liu AL, Xie HJ, Xie HY, Liu J, Yin J, Hu JS, Peng CY. Association between fat mass and obesity associated (FTO) gene rs9939609 A/T polymorphism and polycystic ovary syndrome: a systematic review and meta-analysis. BMC Med Genet 2017;18:89.

Marenne G, Real FX, Rothman N, Rodríguez-Santiago B, Pérez-Jurado L, Kogevinas M, García-Closas M, Silverman DT, Chanock SJ, Génin E, Malats N. Genome-wide CNV analysis replicates the association between GSTM1 deletion and bladder cancer: a support for using continuous measurement from SNP-array data. BMC Genomics 2012;13:326.

Moghanloo MN, Mohammadzadeh NA, Lotfi H, Mahmoudi R, Abbasi M, Alipour FG, Shool F, Porfar S, Zarghami N. Polymorphism rs9939609 of Fat Mass and obesity-associated gene correlation with Leptin level of obese women suffered from type 2 diabetes. Curr Diabetes Rev 2017 Sep 15 [Epub]. https://doi.org/10.2174/15733998136661 70915125043.

Mutie PM, Giordano GN, Franks PW. Lifestyle precision medicine: the next generation in type 2 diabetes prevention? BMC Med 2017;15:171.

Niemann B, Rohrbach S, Miller MR, Newby DE, Fuster V, Kovacic JC. Oxidative stress and cardiovascular risk: obesity, diabetes, smoking, and pollution: part 3 of a 3-part series. J Am Coll Cardiol 2017;70:230251.

O'Rahilly S, Farooqi IS. The genetics of obesity in humans. In: De Groot LJ, Chrousos G, Dungan K, Feingold KR, Grossman A, Hershman JM, Koch C, Korbonits M, McLachlan R, New M, et al., editors. Endotext. South Dartmouth (MA); MDText.com, Inc.; 2000.

Reho JJ, Rahmouni K. Oxidative and inflammatory signals in obesity-associated vascular abnormalities. Clin Sci (Lond) 2017;131:1689-1700.

Rivera M, Locke AE, Corre T, Czamara D, Wolf C, Ching-Lopez A, Milaneschi Y, Kloiber S, Cohen-Woods S, Rucker J, Aitchison KJ, Bergmann S, Boomsma DI, Craddock N, Gill M, Holsboer F, Hottenga JJ, Korszun A, Kutalik Z, Lucae S, Maier W, Mors O, Müller-Myhsok B, Owen MJ, Penninx BWJH, Preisig M, Rice J, Rietschel M, Tozzi F, Uher R, Vollenweider P, Waeber G, Willemsen G, Craig IW, Farmer AE, Lewis CM, Breen G, McGuffin P. Interaction between the FTO gene, body mass index and depression: meta-analysis of 13701 individuals. Br J Psychiatry 2017;211:70-76.

Shaw PM, Chandra V, Escobar GA, Robbins N, Rowe V, Macsata R. Controversies and evidence for cardiovascular disease in the diverse His- 
panic population. J Vasc Surg 2017 Sep 23 [Epub]. https://doi.org/ 10.1016/j.jvs.2017.06.111.

Tremmel M, Gerdtham UG, Nilsson PM, Saha S. Economic burden of obesity: a systematic literature review. Int J Environ Res Public Health 2017;14. pii: E435. https://doi.org/10.3390/ijerph14040435.

Zhang X, Lin J, Wu X, Lin Z, Ning B, Kadlubar S, Kadlubar FF. Associa- tion between GSTM1 copy number, promoter variants and susceptibility to urinary bladder cancer. Int J Mol Epidemiol Genet 2012;3:228236.

Zhou Y, Hambly BD, McLachlan CS. FTO associations with obesity and telomere length. J Biomed Sci 2017;24:65. 